\title{
CRYOGENIC MILLING OF METASTABLE AUSTENITIC STAINLESS STEEL AISI 347
}

\author{
K. Gutzeit ${ }^{1 *}$, S. Basten ${ }^{1}$, B. Kirsch ${ }^{1}$, J.C. Aurich ${ }^{1}$ \\ ${ }^{1}$ TU Kaiserslautern, Institute for Manufacturing Technology and Production Systems, 67663 Kaiserslautern, Germany \\ ${ }^{*}$ Corresponding author; kevin.gutzeit@mv.uni-kl.de
}

\begin{abstract}
The metastable austenitic stainless steel AISI 347 offers the possibility to induce a phase transformation from $\gamma$-austenite to $\varepsilon$ - and $\alpha^{\prime}$-martensite when machining. This knowledge is well understood during cryogenic turning and was already applied to improve the surface morphology of metastable austenitic steel. However, the potential of this in-process hardening method is so far limited to rotationally symmetrical components. The aim of this study is to investigate deformation induced phase transformation during cryogenic milling, aiming at an improved surface morphology and at the resulting beneficial surface properties of the workpiece for parts with complex geometries.
\end{abstract}

\section{Keywords:}

Cryogenic milling; Surface morphology; Deformation induced phase transformation

\section{INTRODUCTION}

The surface morphology of a technical component has a decisive impact on its application behavior [Jawahir 2011]. Besides a low roughness, a strengthened surface layer is highly desirable. Cutting can alter the metallurgical and mechanical properties of the workpiece surface layer. Therefore, it is necessary to investigate causal correlations between the process input variables and the occurring thermo-mechanical load with the resulting surface layer properties [Brinksmeier 2018]. It was reported for various metals, that cutting can cause an increase in the microhardness in the surface layer. This can be traced back to strain hardening mechanisms, such as twinning, grain refinement, or an increase in dislocation density [Jawahir 2016, Pu 2014, Rotella 2014].

Metastable austenitic stainless steels offer the possibility that phase transformations from $y$-austenite to $\varepsilon$ - and $\alpha^{\prime}$ martensite can occur [Angel 1954], which results in beneficial alternations of the mechanical properties. These phase transformations occur concurrent with the mentioned strain hardening mechanisms and therefore further increase the microhardness of the machined materia [Yi 2016, Zhang 2018]. Besides material specific properties such as the chemical composition [Angel 1954, Eichelmann 1953] or the investigated batch [Kirsch 2019], the phase transformation is mainly influenced by the thermo-mechanical impact on the material [Hecker 1982, Olson 1975]. High Hertzian contact stresses and low temperatures increase the probability of phase transformations on a single shear band. This results in an increase of the overall $\alpha$-martensite content in the surface layer of the material [Das 2011, Olson 1972, Olson 1975].

This knowledge can be used to achieve deformationinduced phase transformations in the surface layer simultaneously to the part shaping via cutting, thus representing a hybrid cutting process. Cryogenic media are beneficial to decrease the workpiece temperature, promoting the phase transformations [Becker 2018, Hotz 2018]. Furthermore, the reduction of the workpiece temperature hinders the dynamic recrystallization during cutting which promotes strain hardening and therefore a further increase in microhardness [Bacca 2015, Rotella 2014]. The cutting parameters can also have an influence on the thermo-mechanical load and therefore on the martensite content [Mayer 2018]. The martensite content can be modeled as a function of the process forces and the process temperature [Hotz 2020], which allows for an advanced process control. The correlations between input variables, thermo-mechanical loads and the resulting workpiece properties during cryogenic turning are well understood and lead to improvements in the microhardness [Hotz 2019], fatigue behavior [Smaga 2019] and wear resistance [Fröhlich 2015] of the machined workpiece. However, since this was so far only investigated for turning processes, there are strict limitations to the design of components for which this hybrid cutting process can be applied. The aim of this work is to transfer the possibilities from turning operations to milling operations. Therefore, it has to be investigated, whether or not a phase transformation from $y$-austenite to $\varepsilon$ - and $\alpha$ '-martensite is possible during cryogenic milling. For this purpose, the 
thermo-mechanical load during cryogenic milling is investigated and possible correlations to the resulting workpiece surface layer are characterized.

\section{EXPERIMENTAL SETUP}

\subsection{Machining Experiments}

All experiments were carried out on a 5-axis machining center (Deckel Maho Gildemeister DMU 70 eVolution ${ }^{1}$ ). Solution annealed AISI 347-workpieces with a crosssection of $10 \times 10 \mathrm{~mm}^{2}$ and a length of $50 \mathrm{~mm}$ were machined. The chemical composition of the workpiece material is given in Tab. 1. The width of cut was set to $a_{e}=1 \mathrm{~mm}$ and the depth of cut to $a_{p}=10 \mathrm{~mm}$. CO $C_{2}$ was delivered from a siphoned gas cylinder at ambient temperature and supplied to the process via two expansion nozzles. A mass flow of $0.75 \mathrm{~kg} / \mathrm{min}$ and an outlet temperature of $-78.5^{\circ} \mathrm{C}$ [Barber 1966] resulted at the applied nozzle with an outlet diameter of $0.75 \mathrm{~mm}$. A fouredged end mill (RF $100 \mathrm{Ti}$ - Guehring $\mathrm{KG}^{1}$ ) made of cemented carbide (DK 460 UF, WC: $90 \%$, Co: $10 \%$ ) with a Ti-Al-N coating and a diameter of $10 \mathrm{~mm}$ was used. The manufacturer specified a corner radius of $R=0.5 \mathrm{~mm}$, a rake angle of $\gamma=5^{\circ}$, a clearance angle of $\alpha=10^{\circ}$ and a cutting-edge radius of $r_{\beta}=5 \mu \mathrm{m}$. The experimental setup is depicted in Fig. 1

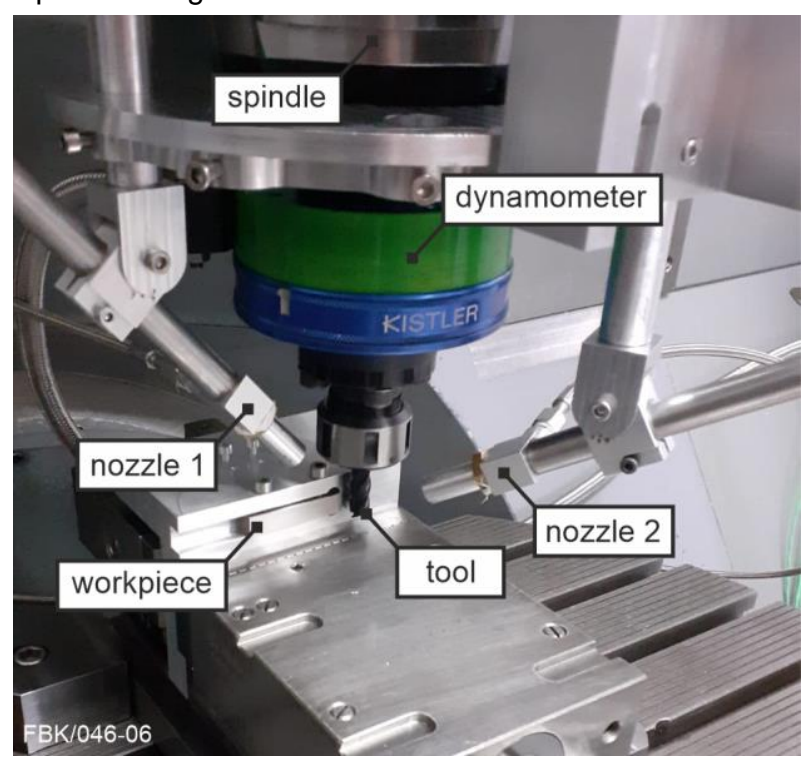

Fig. 1: Experimental Setup.

The influence of the cutting speed $v_{c}$, the feed per tooth $f_{z}$ as well as the milling strategy and the usage of a precooling were examined according to Tab. 2. For statistical verification, three workpieces were milled for each case. A uniform workpiece temperature of $22{ }^{\circ} \mathrm{C}$ was ensured before starting each test. The precooling was realized by moving the cooling system along the feed path without tool engagement at a constant cutting speed of $\mathrm{v}_{\mathrm{c}}=50 \mathrm{~m} / \mathrm{min}$ and a feed velocity of $\mathrm{V} f=0.51 \mathrm{~m} / \mathrm{min}$.

\subsection{Measurement Technology}

The temperature was measured inside the workpiece using $\mathrm{K}$ thermocouples $(\mathrm{NiCr}-\mathrm{Ni})$ with a diameter of $1 \mathrm{~mm}$. Three thermocouples were positioned inside eroded holes along the feed path with a respective distance of $15 \mathrm{~mm}$ to each other. Each hole was filled with thermal paste before the insertion of the thermocouple. The distance between the thermocouple and the final surface was $1 \mathrm{~mm}$. A sampling frequency of $1 \mathrm{kHz}$ was used. Two representative temperature profiles taken from Case 1 and Case 3 are depicted in Fig. 2, in dependence of the feed path of the tool.

Tab. 2: Cases investigated during the experiments.

\begin{tabular}{|c|c|c|c|c|}
\hline Case & $v_{c}$ & $f_{z}$ & Strategy & Precooling \\
& in $\mathrm{m} / \mathrm{min}$ & in $\mathrm{mm}$ \\
\hline 1 & 50 & 0.08 & Down milling & - \\
\cline { 2 - 5 } 2 & 50 & 0.02 & Down milling & - \\
\cline { 2 - 5 } 3 & 50 & 0.08 & Down milling & $X$ \\
\cline { 2 - 5 } 4 & 50 & 0.08 & Up milling & - \\
\cline { 2 - 5 } 5 & 50 & 0.08 & Up milling & $X$ \\
\cline { 2 - 5 } 6 & 250 & 0.08 & Down milling & - \\
\cline { 2 - 5 } 7 & 250 & 0.08 & Down milling & $X$ \\
\hline
\end{tabular}

Since a precooling is used for Case 3 , the respective starting temperature is significantly decreased. Apart from that, the course of the two temperature profiles is considered roughly identical. At first a local minimum is observed, as the cryogenic cooling leads to a decreasing workpiece temperature. Then, the temperature rises because of the heat introduced by the tool during cutting. A local maximum $T_{\operatorname{Max}}$ is reached as a result of the superposition of the heat introduced by the tool and the heat dissipated by the coolant. Consequently, the value measured at the local maximum $\mathrm{T}_{\mathrm{Max}}$ is used as an indicator for the thermal load within the workpiece.

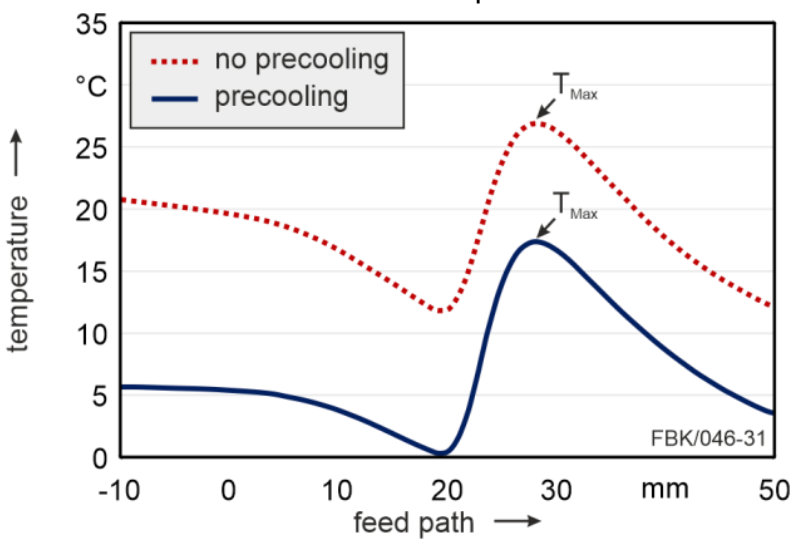

tool: RF 100 Ti

cemented carbide DK 460 UF; $\mathrm{D}=10 \mathrm{~mm}$

Ti-Al-N coating; $z=4 ; r_{\beta}=5 \mu \mathrm{m}$

workpiece: AISI 347

solution annealed $(1323 \mathrm{~K} / 35 \mathrm{~min})$

$10 \mathrm{~mm} \times 10 \mathrm{~mm} \times 50 \mathrm{~mm}$

cutting parameters: $a_{e}=1 \mathrm{~mm} ; v_{c}=50 \mathrm{~m} / \mathrm{min}$ $a_{\mathrm{p}}=10 \mathrm{~mm} ; \mathrm{f}_{\mathrm{z}}=0.08 \mathrm{~mm}$ cooling strategy: $\mathrm{CO}_{2}$, external cooling; $\dot{\mathrm{m}}=1.5 \mathrm{~kg} / \mathrm{min}$

Fig. 2: Representative temperature profile measured for Case 1 and Case 3.

During the cryogenic milling, a rotating dynamometer (Kistler Type 9123C ${ }^{1}$ ) was used to measure the process forces with a sampling frequency of $15 \mathrm{kHz}$. The resulting force was composed by vector addition (see Eq. (1)) of the force components $F_{x}, F_{y}$ and $F_{z}$.

$F_{\text {res }}=\sqrt{F_{x}^{2}+F_{y}^{2}+F_{z}^{2}}$

Tab. 1: Chemical composition of metastable austenitic steel AISI 347 in wt\%.

\begin{tabular}{|ccccccccccc|}
\hline $\mathrm{C}$ & $\mathrm{Cr}$ & $\mathrm{Ni}$ & $\mathrm{N}$ & $\mathrm{Nb}$ & $\mathrm{Mn}$ & $\mathrm{Mo}$ & $\mathrm{Si}$ & $\mathrm{Cu}$ & $\mathrm{Fe}$ & \\
\hline 0.021 & 17.19 & 9.44 & 0.38 & 0.38 & 1.55 & 0.23 & 0.59 & 0,11 & Rest \\
\hline
\end{tabular}

MM Science Journal | 2021 | NOVEMBER - Special Issue on HSM2021 
The surface topography was determined by measuring the average roughness $\mathrm{Ra}$ at the machined surface. Nine measurements were carried out for each workpiece resulting in 27 measurements per case. The surface roughness was measured by using the tactile measurement device MarSurfGD $120^{1}$ over a measuring length of In $=4 \mathrm{~mm}\left(\lambda_{\mathrm{c}}=0.8 \mathrm{~mm}\right)$.

Since the deformation-induced phase transformation leads to a change in the permeability of the material, a magnetic sensor (Feritscope FMP30 ${ }^{1}$ ) was used to determine the amount of $\alpha^{\prime}$-martensite. The $\alpha^{\prime}$-martensite content was measured at five equidistant points with a respective distance of $5 \mathrm{~mm}$ along the feed path and three points perpendicular to the feed direction with a distance of $3 \mathrm{~mm}$ on each workpiece. Five measurements were carried out at each of the 15 locations, resulting in a total of 75 measurements. Additionally, three workpieces were measured before they were cryogenically machined in order to compare the results with the initial state. Since the paramagnetic $\varepsilon$-martensite cannot be measured with the magnetic sensor, additional micrographs are prepared and etched using Beraha II.

The microhardness was measured using the microhardness device MicroMet $5100^{1}$ with a test load of $0.098 \mathrm{~N}$ (HV0.01). For statistical verification, 10 measurements were conducted in the near surface layer (distance: $20 \mu \mathrm{m}$ ) of the workpiece. In order to evaluate the increase in microhardness, five measurements were carried out in the bulk, which is not affected by the cryogenic milling. Two representative measuring imprints are depicted in Fig. 3.

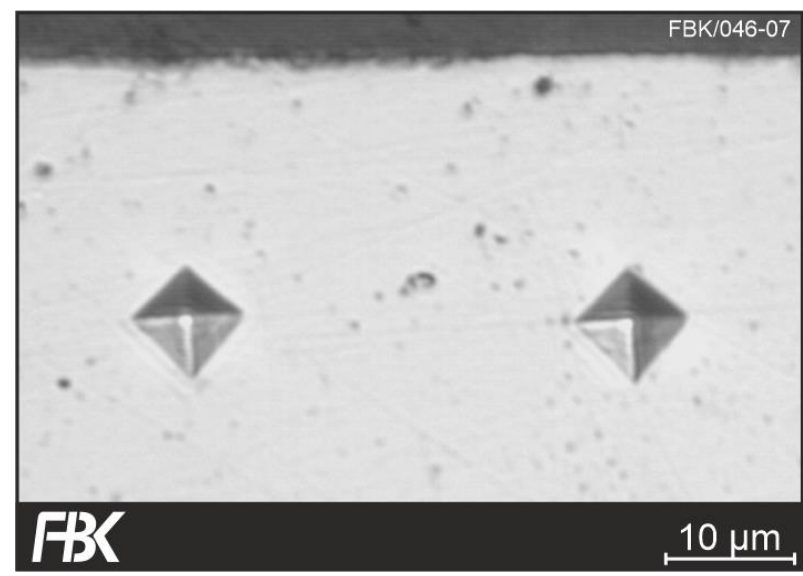

Fig. 3: Representative microhardness imprints.

\section{RESULTS AND DISCUSSION}

\subsection{Thermo-Mechanical Load}

In Fig. 4 the temperatures measured inside the workpiece are shown. These temperatures result from the superposition of the thermal load during machining and the heat removed by the coolant. The influence of the feed per tooth is depicted in Fig. 4 (a). In this figure, it is clear, that a decreasing feed per tooth leads to lower temperatures in the workpiece at a distance of $1 \mathrm{~mm}$ to the surface. Since the mass flow is kept constant, more $\mathrm{CO}_{2}$ is applied in this case to the contact zone, as there is a longer duration of cooling compared to the higher feed rate. The longer duration of cryogenic cooling results in more heat that is removed from the contact zone which is why lower temperatures are measured here. Furthermore, by using a lower feed per tooth, less material is removed per cut. As a result, the cutting power is lower. This results in less heat generation, which has also a beneficial influence regarding the temperature.

In Fig. 4 (b) the influence of the cutting speed on the temperature is shown. Increasing the cutting speed leads to lower temperatures measured $1 \mathrm{~mm}$ inside of the workpiece whether or not a precooling is used. The friction as well as the strain rates in the primary and secondary deformation zone are increased at higher cutting speeds which generally results in higher temperatures and therefore a higher thermal load [Jaspers 2002].
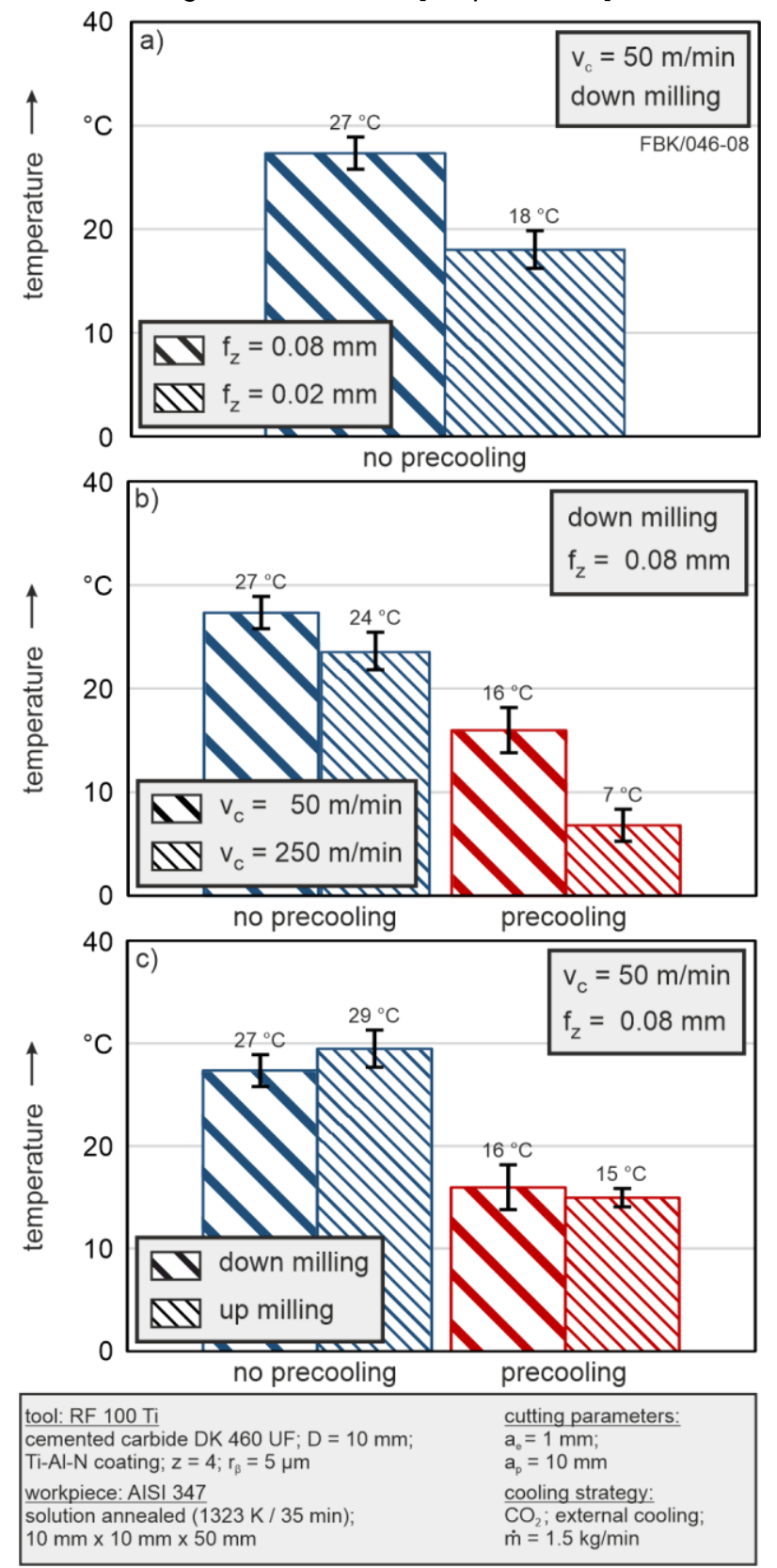

Fig. 4: Resulting temperatures for the cases investigated.

The amount of heat dissipated by the coolant also decreases since the higher cutting speed leads to an increasing feed velocity at constant feed per tooth, reducing the cooling time. However, in our investigations an increasing temperature at higher cutting speeds is not observed. This could be explained with the short contact times reducing the heat conduction in the workpiece. A lower cutting speed increases the contact time in which the tool, workpiece and chip are in contact to each other. As a 
result, there is more time available for the heat generated to dissipate into the workpiece, which is why higher temperatures can occur inside the workpiece surface layer at a distance of $1 \mathrm{~mm}$. However, it can be expected that the temperatures in the very near surface layer are higher due to the promoted friction and strain rates at higher cutting speeds [Jaspers 2002, Riza 2016]. Unfortunately, this region can hardly be examined via temperature measurements.

If a precooling is used, the temperature in the workpiece surface when machining is significantly decreased due to a lower initial temperature of the workpiece. The sharp drop in temperature is observed for both, a cutting speed of $\mathrm{v}_{\mathrm{c}}=50 \mathrm{~m} / \mathrm{min}$ and $\mathrm{v}_{\mathrm{c}}=250 \mathrm{~m} / \mathrm{min}$. The precooling of the workpieces has a slightly lower influence at a cutting speed of $v_{c}=50 \mathrm{~m} / \mathrm{min}$. This indicates that more of the heat generated during the cutting process is dissipated into the workpiece surface layer as a result of the longer contact time of the tool and the workpiece.

Using up milling instead of down milling without a precooling leads to a slight increase in temperature inside the workpiece surface layer (see Fig. 4 (c)). Since the cutting parameters are identical, the cooling conditions and the resulting amount of heat dissipated by the coolant are considered to be roughly the same. Consequently, more heat is generated during up milling. During up milling the cutting edge engages the workpiece material below the minimum undeformed chip thickness favouring ploughing phenomena instead of chip formation, which leads to more friction and thus a higher generation of heat. If a precooling is used, the temperature decreases for both, the up and the down milling strategy and hence regardless of the milling strategy used.

The resulting forces calculated according to Eq. (1) are depicted in Fig. 5. Increasing the feed per tooth causes a higher mechanical load (see Fig.5(a)) due to the increasing chip thickness.

The influence of the cutting speed on the mechanical load is depicted in Fig. 5 (b). By using a higher cutting speed, the resulting force is decreased, despite of whether or not a precooling is used. A higher thermal load can be a possible reason for this as the material resistance would decrease due to a thermally induced softening of the workpiece material. This promotes the aforementioned assumption that a higher thermal load occurs in the very near surface layer at higher cutting speeds, despite the lower temperatures measured in the workpiece surface layer at a depth of $1 \mathrm{~mm}$. When the precooling is used, a slight increase of the resulting force is observed for both cutting speeds due to thermally induced strengthening as a result of the lower temperatures in the cutting zone achieved by the precooling.

Another possible explanation for the higher resulting forces at a lower cutting speed could be the formation of build-up edges (BUE) during the milling process. Decreasing the cutting speed promotes the formation of BUEs on the cutting edge [Ahmed 2017]. As the time in which the tool is in contact with the workpiece increases, the adhesion of microchips is promoted leading to a BUE. The adhesion of microchips on the cutting edge can alter its geometry which may lead to decreasing sharpness of the cutting edge or an increasing negative rake angle which in term increases the resulting force [Atlati 2015]. However, the formation of BUE was not observed during our investigations.

Changing the milling strategy from down milling to up milling leads to an increase of the resulting force (Fig. 5 (c)). The increase of the mechanical load occurs because of ploughing effects as up milling promotes a higher amount of plastic deformation at the workpiece surface. This is due to the kinematics of the milling strategy. During up milling the cutting edge enters the cutting zone at a chip thickness of zero. As long as the minimum chip thickness is not reached, no chip formation occurs. The consequences are ploughing effects between the workpiece and the tool leading to elastic and plastic deformation and therefore higher resulting forces. A slight increase of the resulting force is observed when a precooling is used for both milling strategies investigated. This is due to a thermal strengthening of the workpiece material since the precooling promotes lower workpiece temperatures (see Fig. 4 (c)).
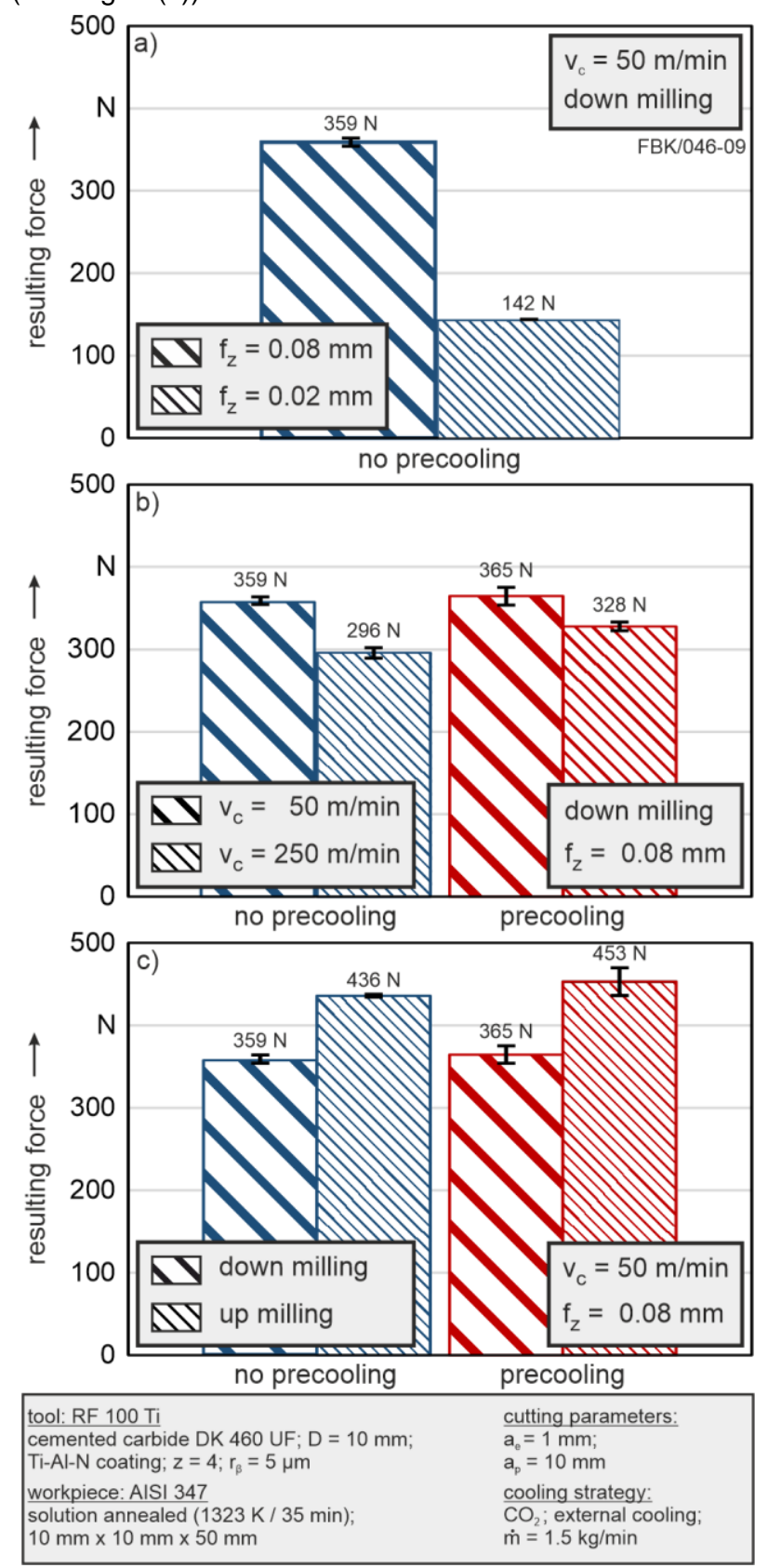

Fig. 5: Resulting forces depending on the cases investigated.

\subsection{Surface Morphology}

The average roughness $\mathrm{Ra}$ is depicted in Fig. 6 . The feed per tooth has the highest influence on the average 
roughness. In contrast, the influences of the other parameters investigated are comparatively low, being in the range of the standard deviation. By decreasing the feed per tooth, the average roughness is reduced as a result of a decreased kinematic roughness (see Fig. 6 (a)).
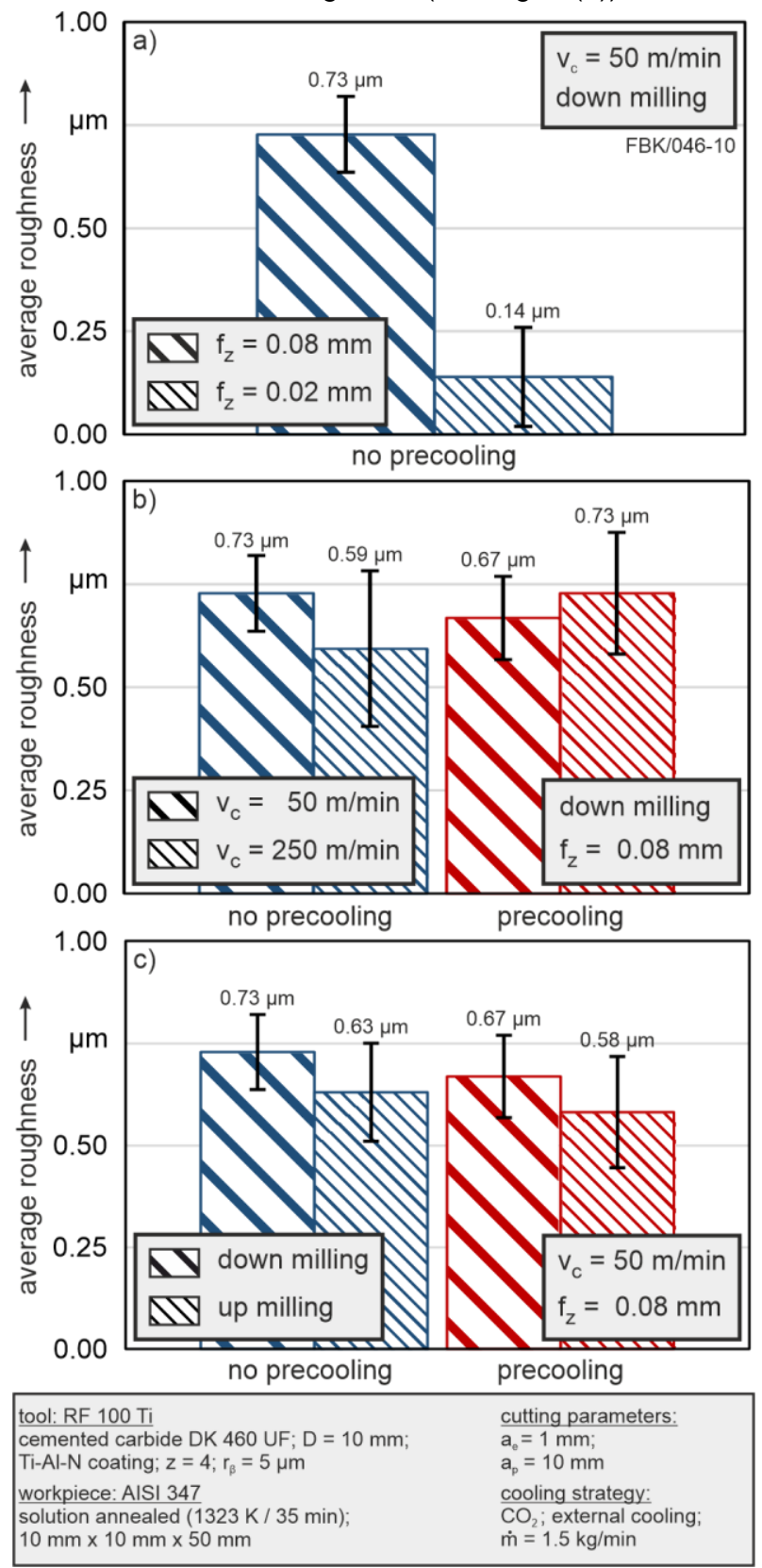

Fig. 6: Average roughness depending on the cases investigated.
When no precooling is used, a slightly decreased average roughness is achieved by increasing the cutting speed (see Fig. 6 (b)). This could be led back to less BUE which could reduce the surface quality, as they are more likely to occur at a low cutting speed. The usage of a precooling results in a marginally improved surface roughness at a low cutting speed, while the opposite is observed when a high cutting speed is used. As the precooling reduces the workpiece temperature, the material behaves more brittle, which in term reduces the smearing effects on the workpiece surface during machining, favouring the surface quality. However, this is not observed at an increased cutting speed. A possible explanation could result from the higher temperatures in the very near surface layer that are expected at the higher cutting speed. If the workpiece temperature is sufficiently high, smearing effects still occur, which would increase the surface roughness.

By changing the milling strategy from down milling to up milling, a slight decrease of the average roughness is visible (see Fig. 6 (c)). During up milling, a better chip removal from the machining zone was observed, since the rotation of the tool carries the chips away from the machined workpiece surface during cutting. This promotes a higher surface quality, as the potential damage caused by the scratching of the chips is prevented.

No $\alpha$ '-martensite content is detected when measuring the initial, solution annealed state of the workpiece surface $(0.06 \pm 0.03$ vol. $-\%)$. An increase of the $\alpha^{\prime}$-martensite content is only detected for three of the cases investigated which are listed in Tab. 3.

The highest $\alpha^{\prime}$-martensite content is measured when the feed per tooth is decreased from $f_{z}=0.08 \mathrm{~mm}$ to $f_{z}=0.02 \mathrm{~mm}$. By reducing the feed per tooth, the temperature in the cutting zone, as well as the occurring forces decrease. A decreasing temperature promotes a higher amount of martensite content due to a lower thermal load. However, lower forces and consequently lower mechanical loads indicate less plastic deformation during the cutting process which would inhibit the phase transformation from $y$-austenite to $\varepsilon$ - and $\alpha^{\prime}$-martensite. As a higher $\alpha^{\prime}$-martensite content is measured at a low feed per tooth, the resulting thermo-mechanical load still seems more favorable for the phase transformation. A possible reason is that the decrease of the thermal load in the near surface layer is more significant in comparison to the lower mechanical load. Another possible explanation might be that the decreased resultant forces measured for $\mathrm{f}_{\mathrm{z}}=0.02 \mathrm{~mm}$ do not lead to a sufficient reduction of the plastic deformation in the near surface layer.

Using a higher cutting speed does not lead to a significant increase of the $\alpha^{\prime}$-martensite content in the workpiece surface layer. Increasing the cutting speed results in lower forces and a lower temperature measured in the workpiece.

Tab. 3: $\alpha^{\prime}$-martensite content measured inside the workpiece surface layer in regard to the cases investigated.

\begin{tabular}{|c|c|c|c|c|c|}
\hline Case & $\begin{array}{c}\mathrm{v}_{\mathrm{c}} \\
\text { in } \mathrm{m} / \mathrm{min}\end{array}$ & $\begin{array}{c}f_{z} \\
\text { in } \mathrm{mm}\end{array}$ & Operation & Precooling & $\begin{array}{l}\alpha^{\prime} \text {-martensite content } \\
\text { in vol.- } \%\end{array}$ \\
\hline 1 & 50 & 0.08 & Down milling & - & $0.05 \pm 0.04$ \\
\hline 2 & 50 & 0.02 & Down milling & - & $0.34 \pm 0.03$ \\
\hline 3 & 50 & 0.08 & Down milling & $\mathrm{X}$ & $0.05 \pm 0.02$ \\
\hline 4 & 50 & 0.08 & Up milling & - & $0.27 \pm 0.04$ \\
\hline 5 & 50 & 0.08 & Up milling & $x$ & $0.26 \pm 0.02$ \\
\hline 6 & 250 & 0.08 & Down Milling & - & $0.03 \pm 0.02$ \\
\hline 7 & 250 & 0.08 & Down milling & $\mathrm{X}$ & $0.04 \pm 0.02$ \\
\hline
\end{tabular}

MM Science Journal | 2021 | NOVEMBER - Special Issue on HSM2021 
Despite the lower temperatures measured, the occurring thermo-mechanical load does not seem sufficient enough to favour a phase transformation. This promotes the previously mentioned assumption, that the temperatures and the respective thermal load in the very near surface layer are higher at an increased cutting speed. An increased thermal load leads to decreasing forces due to thermal softening and counteracts the phase transformation, which is why no significant increase of the $\alpha^{\prime}$-martensite content is measured.

When changing the milling strategy from down milling to up milling, a higher amount of $\alpha^{\prime}$-martensite content is observed. Using up milling instead of down milling leads to an increase of the temperature as well as the resulting forces. The higher thermo-mechanical load results from ploughing effects and a higher amount of plastic deformation in the surface layer of the workpiece. In comparison to the increasing forces, and therefore the higher amount of plastic deformation, the rise in temperature is comparably low, resulting in a favorable thermo-mechanical load and therefore a promoted phase transformation towards the $\varepsilon$ - and $\alpha$ '-martensite.

Using a precooling during milling does not have a significant effect on the phase transformation, regardless of the lower temperatures that occur here. This means that the influence of a used precooling on the phase transformation can be considered neglectable for all parameter settings investigated here.

To further investigate the phase transformation towards the deformation induced martensite after cryogenic milling, micrographs were made depicting the workpiece surface layer parallel to the feed path. In Fig. 7, exemplarily micrographs etched with Beraha II are shown for both milling strategies investigated. For down milling (Fig. 7 (a)) the surface layer of a workpiece from Case 2 is shown while a workpiece that is machined with the parameter settings from Case 5 is used to depict the surface layer after up milling (Fig. 7 (b)). The martensitic needle structure, colored in black, can be observed in the surface layer of both workpieces shown. This indicates that a deformation induced phase transformation was achieved during cryogenic milling. Comparing both micrographs shows that the orientation of the martensitic structure differs when the milling strategy is changed. This results from the different cutting directions, changing the course of the mechanical load and therefore the elastic and plastic deformation.

The microhardness measured in the near surface layer (distance $20 \mu \mathrm{m}$ ) of the workpiece in dependence of the investigated parameter settings is depicted in Fig. 8. Even if no phase transformation was achieved, an increased microhardness at the near surface of the workpiece in comparison to the core microhardness inside the bulk material is observed for all cases, due to strain hardening effects.

Using a lower feed per tooth leads to an increasing microhardness as it promotes the deformation induced phase transformation from $\gamma$-austenite towards the $\varepsilon$ - and a'-martensite (see Fig. 8 (a)).

The influence of the cutting speed on the microhardness is depicted in Fig. 8 (b). Increasing the cutting speed results in a slightly lower microhardness. The decreased microhardness has to be attributed to the influence of strain hardening mechanisms. A higher thermal load in the near surface layer favors a dynamic recrystallization of the machined surface. This dynamic recrystallization counteracts the strain hardening mechanisms, which ultimately leads to a lower microhardness. This further promotes the assumption that the thermal load in the near surface layer increases at higher cutting speeds. By using a precooling, the microhardness increases slightly for both cutting speeds investigated. As the use of a precooling promotes lower temperatures, the dynamic recrystallization during the cryogenic milling process is suppressed. This favors strain hardening mechanisms and therefore an increase in microhardness.
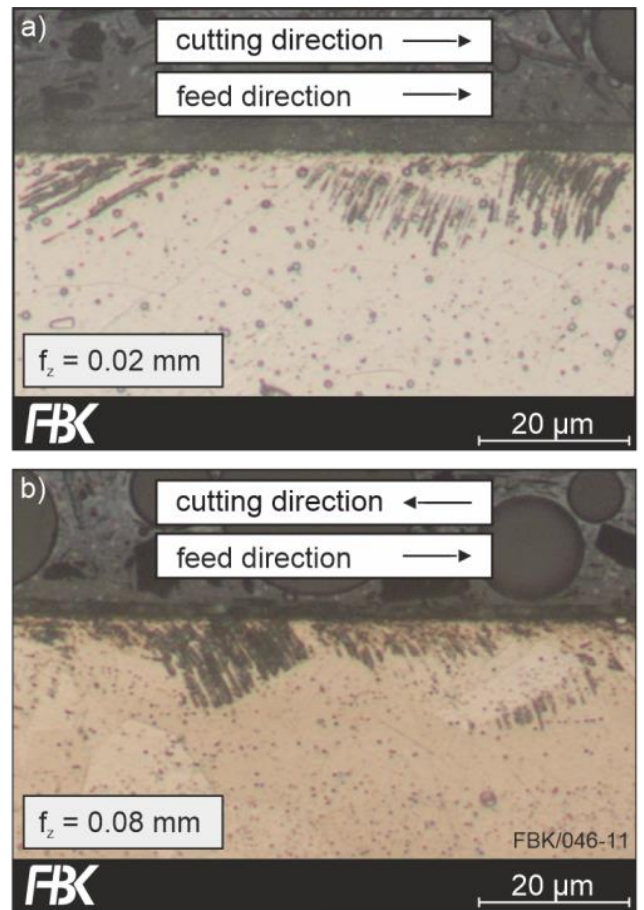

\begin{tabular}{|c|c|}
\hline $\begin{array}{l}\text { tool: RF } 100 \mathrm{Ti} \\
\text { cemented carbide DK } 460 \text { UF; D }=10 \mathrm{~mm} \text {; } \\
\text { Ti-Al-N coating; } z=4 ; r_{\beta}=5 \mu \mathrm{m}\end{array}$ & $\begin{array}{l}\text { cutting parameters: } \\
a_{\mathrm{e}}=1 \mathrm{~mm} ; v_{\mathrm{c}}=50 \mathrm{~m} / \mathrm{min} ; \\
a_{\mathrm{p}}=10 \mathrm{~mm}\end{array}$ \\
\hline $\begin{array}{l}\text { workpiece: AISI } 347 \\
\text { solution annealed }(1323 \mathrm{~K} / 35 \mathrm{~min}) \text {; } \\
10 \mathrm{~mm} \times 10 \mathrm{~mm} \times 50 \mathrm{~mm}\end{array}$ & $\begin{array}{l}\text { cooling strategy: } \\
\mathrm{CO}_{2} ; \text { external cooling; } \\
\dot{\mathrm{m}}=1.5 \mathrm{~kg} / \mathrm{min}\end{array}$ \\
\hline
\end{tabular}

Fig. 7: Depiction of martensite inside the workpiece subsurface (a) for down milling and (b) up milling.

Changing from down milling to up milling results in an increase of the microhardness (Fig. 8 (c)). The favorable thermo-mechanical load when using up milling promotes the phase transformation towards deformation induced martensite, which in term leads to a higher microhardness. Additionally, strain hardening is promoted due to the increasing elastic and plastic deformation of the material during up milling as a result of the ploughing effects. The usage of a precooling during up milling further promotes an increased microhardness as the dynamic recrystallization in suppressed.

The investigation of the microhardness in the near surface layer of the workpiece shows, that the best results are achieved using up milling especially with an additional precooling (Case 5). Although the highest content of $\alpha$ '-martensite is achieved by reducing the feed per tooth (see Case 2) the change of the milling strategy from down milling to up milling shows the highest influence on the microhardness. This might be due to a higher content of paramagnetic $\varepsilon$-martensite, that cannot be detected when measuring the change in permeability. Another explanation is the more favorable thermo-mechanical load, promoting strain hardening mechanisms. This would lead to a higher increase in microhardness in comparison to the content of deformation induced $\alpha$ '-martensite. 


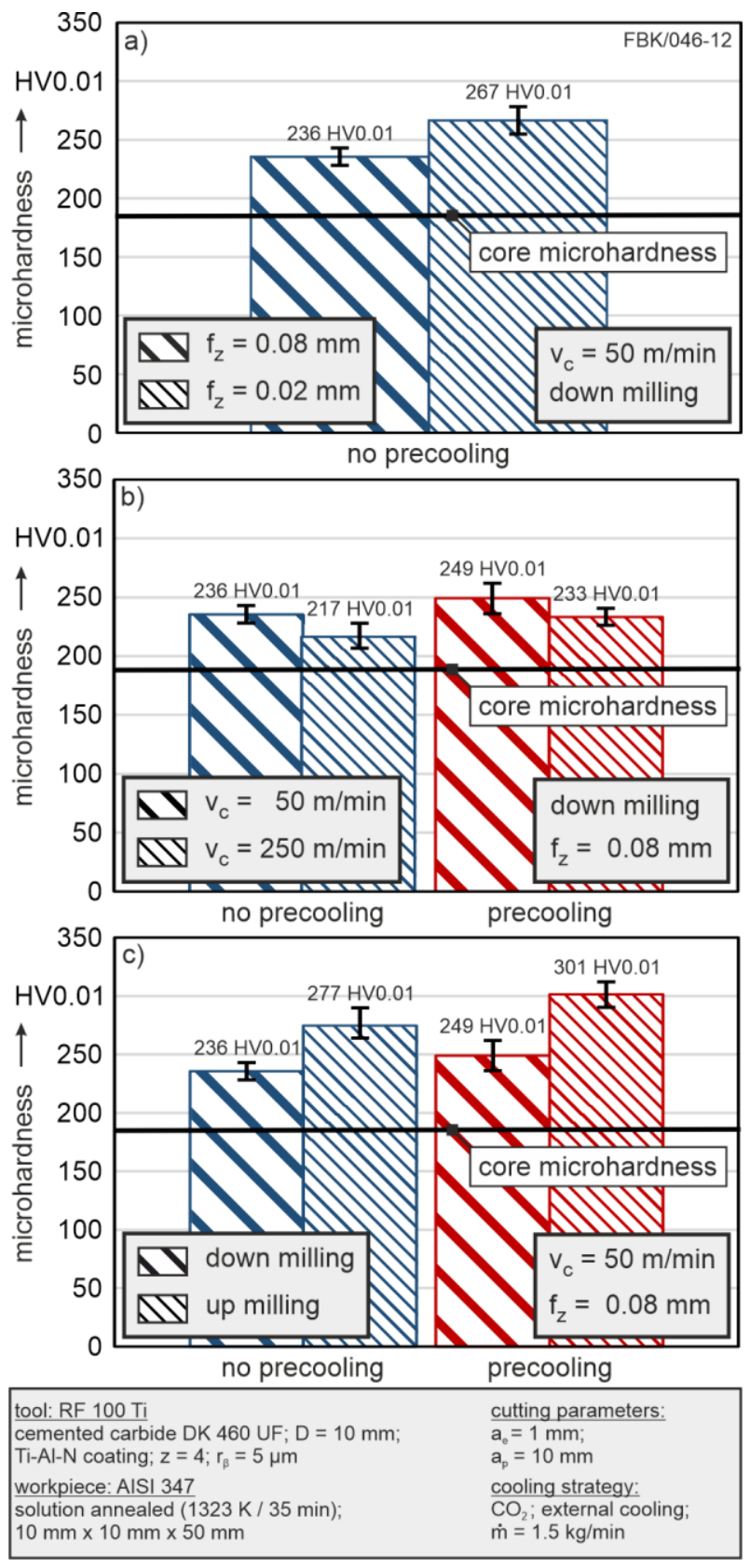

Fig. 8: Resulting microhardness depending on the cases investigated.

\section{SUMMARY}

The deformation-induced phase transformation of metastable austenitic steels in manufacturing processes is a promising approach for strengthening the surface layer integrated in the shaping process. So far, this hybrid manufacturing process has been extensively characterized for turning. This work shows that these correlations obtained from turning operations cannot be directly transferred to milling operations. In particular, the higher complexity and the variability of the kinematics of the milling process limit the transferability.

Nevertheless, the results of this paper show that small amounts of $\alpha^{\prime}$-martensite are measured in the workpiece surface layer, proving that a deformation induced phase transformation is possible when cryogenic milling.

Decreasing the feed per tooth leads to the highest $\alpha^{\prime}$-martensite content, as the thermal load is reduced significantly. Moreover, the lower feed per tooth results in a highly decreased surface roughness further improving the surface morphology.

An increasing cutting speed actually shows decreasing temperatures in the workpiece, though not favoring the deformation-induced phase transformation. Additionally, lower forces and a lower microhardness are observed at higher cutting speeds, indicating a higher thermal load in the near surface area which contradicts the lower temperatures measured.

A substantial reduction of temperature, by means of cryogenic precooling was demonstrated. However, the reduced temperature did not result in a favorable thermomechanical load in order to promote a phase transformation. Despite that, using a precooling results in an increased microhardness, as the lower temperatures counteract the dynamic recrystallization and therefore favor the introduction of strain hardening mechanisms into the surface layer.

Due to an increased amount of plastic deformation, the change of the milling strategy from down milling to up milling leads to the highest increase in microhardness, especially if an additional precooling is used. The increased microhardness results from the superposition of the phase transformation from $\gamma$-austenite to $\varepsilon$ - and $\alpha^{\prime}$-martensite and the introduction of strain hardening mechanisms into the surface layer of the workpiece.

In further investigations, the potential to improve the surface morphology during cryogenic milling will be examined in more detail. In particular, the investigation of up milling while using a low feed per tooth is of great interest. With this parameter setting, a favorable thermo-mechanical load is expected, due to a high amount of plastic deformation and a significant reduction of the thermal load in the workpiece surface layer. As a result, the deformation-induced phase transformation from $\gamma$-austenite to $\varepsilon$ - and $\alpha$ '-martensite as well as strain hardening effects are promoted, offering the potential to further improve the surface morphology.

Additionally, the influence of the geometry of the tool, in particular the variation of the cutting edge radius, will be investigated. Besides observing the microhardness and the average roughness, the residual stresses inside the workpiece surface layer will be investigated in order to further characterize the influence of cryogenic milling on the surface morphology.

\section{ACKNOWLEDGMENTS}

This work was funded by the Deutsche Forschungsgemeinschaft (DFG, German Research Foundation) - project number 172116086 - SFB 926.

${ }^{1}$ Naming of specific manufacturers is done solely for the sake of completeness and does not necessarily imply an endorsement of the named companies nor that the products are necessarily the best for the purpose.

\section{REFERENCES}

[Ahmed 2017] Ahmed, Y.S., Fox-Rabinovich, G., Paiva, J.M., Wagg, T. and Veldhuis, S.C. Effect of Built-Up Edge Formation during Stable State of Wear in AISI 304 Stainless Steel on Machining Performance and Surface Integrity of the Machined Part. Materials, 2017, Vol. 10, pp. 1-15.

[Angel 1954] Angel, T. Formation of Martensite in Austenitic Stainless Steels - Effect of Deformation, Temperature, and Composition. Journal of the Iron Steel Institute, 1954, Vol.177, pp. 165-174. 
[Atlati 2015] Atlati, S., Haddag, B., Nouari, M. and Moufki, A Effect on local friction and contact nature of the Built-Up Edge formation process in machining ductile metals. Tribology International, 2015, Vol. 90, pp. 217-227.

[Bacca 2015] Bacca, M., Hayhurst, D.R. and McMeeking, R.M. Continuous dynamic recrystallization during severe plastic deformation. Mechanics of Materials, 2015, Vol. 90, pp. 148156.

[Barber 1966] Barber, C.R. The Sublimation Temperature of Carbon Dioxide. British Journal of Applied Physics, 1966, Vol.17, No.3, pp. 391-397.

[Becker 2018] Becker, S., Hotz, H., Kirsch, B., Aurich, J.C., von Harbou, E. and Mueller, R. A. Finite Element Approach to Calculate Temperatures Arising During Cryogenic Turning of Metastable Austenitic Steel AISI 347. ASME Journal of Manufacturing Science and Engineering, October 2018, Vol.140, No.10, pp. 101016-1010167.

[Brinksmeier 2018] Brinksmeier, E., Meyer, D., Heinzel, C., Luebben, T., Sölter, J., Langenhorst, L., Frerichs, F., Kaemmler, J., Kohls, E. and Kuschel, S. Process Signatures The Missing Link to Predict Surface Integrity in Machining. Procedia CIRP, 2018, Vol.71, pp. 3-10, ISSN 2212-8271.

[Das 2011] Das, A., Tarafder, S. and Chakraborti, P. C Estimation of Deformation Induced Martensite in Austenitic Stainless Steels. Materials Science and Engineering: A, November 2011, Vol.529, pp. 9-20, ISSN 0921-5093.

[Eichelmann 1953] Eichelmann, G.C. and Hull, T.C. The Effect of Composition on the Temperature of Spontaneous Transformation of Austenite to Martensite in 18-8 Type Stainless Steel. Transactions of the American Society for Metals, 1953, Vol.45, pp. 77-104.

[Froelich 2015] Froelich, D., Magyar, B., Sauer, B., Mayer, P., Kirsch, B., Aurich, J.C., Skorupski, R., Smaga, M., Beck, T. and Eifler, D. Investigation of Wear Resistance of Dry and Cryogenic Turned Metastable Austenitic Steel Shafts and Dry Turned and Ground Carburized Steel Shafts in the Radial Shaft Seal Ring System. Wear, 2015, Vol.328-329, pp. 123-131, ISSN 0043-1648.

[Hecker 1982] Hecker, S.S., Stout, M.G., Staudhammer, K.P. and Smith, J.L. Effects of Strain Rate on Deformation-Induced Transformation in 304 Stainless Steel: Part I. Magnetic Measurements and Mechanical Behavior. Metallurgical Transactions A, April 1982, Vol.13, pp. 619-626.

[Hotz 2018] Hotz, H., Kirsch, B., Becker, S., von Harbou, E., Mueller, R., and Aurich, J.C. Modification of Surface Morphology during Cryogenic Turning of Metastable Austenitic Steel AISI 347 at Different Parameter Combinations with Constant $\mathrm{CO}_{2}$ Consumption per Cut. Procedia CIRP, Vol.77, pp. 207-210, ISSN 2212-8271.

[Hotz 2019] Hotz, H., Kirsch, B., Becker, S., Müller, R., and Aurich, J.C. Combination of Cold drawing and Cryogenic Turning for Modifying Surface Morphology of Metastable Austenitic AISI 347 Steel. Journal of Iron and Steel Research International, November 2019, Vol.26, pp. S. 1188-1198.

[Hotz 2020] Hotz, H., Kirsch, B., and Aurich, J.C. Impact of the Thermomechanical Load on Subsurface Phase Transformations during Cryogenic Turning of Metastable Austenitic Steels. Journal of Intelligent Manufacturing, July 2020.

[Jaspers 2002] Jaspers, S.P.F.C. and Dautzenberg, J.H. Material behaviour in metal cutting: strains, strain raits and temperatures in chip formation. Journal of Materials Processing Technology, 2002, Vol.121, pp. 123-135.

[Jawahir 2011] Jawahir, I.S., Brinksmeier, E., M'Saoubi, R., Aspinwall, D.K., Outeiro, J.C., Meyer, D., Umbrello, D. and Jayal, A.D. Surface Integrity in Material Removal Processes:
Recent advances. CIRP Annals, 2011, Vol.60, No.2, pp. 603626, ISSN 0007-8506.

[Jawahir 2016] Jawahir, I.S., Attia, H., Biermann, D., Duflou, J., Klocke, F., Meyer, D., Newman, S.T., Pusavec, F., Putz, M., Rech, J., Schulze, V. and Umbrello, U. Cryogenic Manufacturing Processes. CIRP Annals, 2016, Vol.65, No.2, pp. 713-736.

[Kirsch 2019] Kirsch, B., Hotz, H., Müller, R., Becker, S., Boemke, A., Smaga, M., Beck, T. and Aurich, J.C. Generation of Deformation-Induced Martensite when Cryogenic Turning Various Batches of the Metastable Austenitic Steel AISI 347. Production Engineering - Research and Development, June 2019, Vol.13, pp. 343-350.

[Mayer 2018] Mayer, P., Kirsch, B., Müller, C., Hotz, H., Müller, R., Becker, S., von Harbou, E., Skorupski, R., Boemke, A., Smaga, M., Eifler, D., Beck, T. and Aurich, J.C. Deformation Induced Hardening when Cryogenic Turning. CIRP Journal of Manufacturing Science and Technology, 2018, Vol.23, pp. 619 , ISSN 1755-5817.

[Olson 1972] Olson, G.B. and Cohen, M. A Mechanism for the Strain-Induced Nucleation of Martensitic Transformations. Journal of the Less Common Metals, 1972, Vol.28, No.1, pp. 107-118.

[Olson 1975] Olson, G.B. and Cohen, M. Kinetics of StrainInduced Martensitic Nucleation. Metallurgical and Materials Transactions A, 1975, Vol.6, pp. 791-795.

[Pu 2014] Pu, Z., Umbrello, D., Dillon Jr., O.W., Lu, T., Puleo, D.A. and Jawahir, I.S. Finite Element Modeling of Microstructural Changes in Dry and Cryogenic Machining of AZ31B Magnesium Alloy. Journal of Manufacturing Processes, April 2014, Vol.16, No.2, pp. 335-343, ISSN 1526-6125.

[Rotella 2014] Rotella, G. and Umbrello, D. Finite Element Modeling of Microstructural Changes in Dry and Cryogenic Cutting of Ti6Al4V Alloy. CIRP Annals, 2014, Vol.63, No.1, pp. 69-72, ISSN 0007-8506.

[Riza 2016] Riza, M. and Adesta, E.Y.T. Investigation of Cutting Temperature for AISI H13 in High Speed End Milling. International Journal of Engineering Materials and Manufacture, 2016, Vol.1, pp. 27-34.

[Smaga 2017] Smaga, M., Skorupski, R., Mayer, P., Kirsch, B., Aurich, J.C., Raid, I., Seewig, J., Man, J., Eifler, D. and Beck, T. Influence of Surface Morphology on Fatigue Behavior of Metastable Austenitic Stainless Steel AISI 347 at Ambient Temperature and $300^{\circ} \mathrm{C}$. Procedia Structural Integrity, 2017, Vol.5, pp. 989-996.

[Smaga 2019] Smaga, M., Boemke, A., Daniel, T., Skorupski, R., Sorich, A. and Beck, T. Fatigue Behavior of Metastable Austenitic Stainless Steels in LCF, HCF and VHCF Regimes at Ambient and Elevated Temperatures. Metals, 2019, Vol.9, pp. 704-721.

[Yi 2016] Yi, H.Y., Yan, F.K., Tao, N.R. and Lu, K. Work Hardening Behavior of Nanotwinned Austenitic Grains in a Metastable Austenitic Stainless Steel. Scripta Materialia, March 2016, Vol.114, pp. 133-136, ISSN 1359-6462.

[Zhang 2018] Zhang, W., Wang, X., Hu, Y. and Wang, S. Predictive Modelling of Microstructure Changes, MicroHardness and Residual Stress in Machining of 304 Austenitic Stainless Steel. International Journal of Machine Tools and Manufacture, August 2018, Vol.130-131, pp. 36-48, ISSN 0890-6955. 